\title{
Bringing I-O Psychology to the Public: But What if We Have Nothing to Say?
}

\author{
Mehmet A. Orhan \\ EM Normandie Business School, Metis Lab, France \\ P. Matthijs Bal \\ University of Lincoln, $U K$
}

Yvonne G. T. van Rossenberg

Radboud University Nijmegen, the Netherlands

Correspondence concerning this paper can be addressed to Mehmet A. Orhan. Email: morhan@em-normandie.fr

In their timely piece, Rogelberg, King and Alonso (2022) eloquently elaborated the reasons why $\mathrm{I}-\mathrm{O}$ science experiences difficulties in reaching the public and presented the tactics of how I-O psychologists could elevate scientific findings to the broader masses. Undoubtedly, there is a growing need for advancing the overall communication and representation of I-O psychology in the eyes of the public, especially when issues in the work and psychology domains get more convoluted than ever. Still, we believe that substantial obstacles exist in the current academic system that prevents scientists and the public from meeting on common grounds. Unlike proposed in the focal article, the reasons why researchers fail to engage with the public are not merely operational, but rather structural by nature. In this commentary, we aim to address these issues by providing an alternative perspective, thereby enhancing our understanding of the complexity of the issue.

We argue that viewing communication between scholars and the public as unidirectional, in the way that only scientists act as the senders of messages while the public passively receives them, is providing only a partial and limited view. In the light of examples presented in the focal article and previously published research in the Industrial and Organizational Psychology journal, not only is it evident that scientists and the public are disconnected, but they have very little in common to share. In addition, this gap between research and practice continues to widen. Thus, we seek to unpack the underlying reasons why existing mechanisms do not allow any relevant and meaningful exchange between theory and practice. We further discuss how this lack of meaningful interaction hinders effective communication between scholars, practitioners, and the broader public in general.

Please cite as: Orhan, M. A., Bal, P. M., \& van Rossenberg, Y. G. T. (2022). Bringing I-O psychology to the public: What if we have nothing to say?. PsyArXiv. https://doi.org/10.31234/osf.io/rnq2e 


\section{Incentives! You again?}

Among the major reasons I-O researchers fail to engage in public-facing activities, insufficient reward structures were cited by Rogelberg et al. (2022). Incentives are particularly important in academic settings because many scholars have raised concerns about how extrinsic incentives shape negatively the culture of academia, the higher education market, and scientific development (Edwards \& Roy, 2017; Harvey, 2020; Smaldino \& McElreath, 2016; van Dalen, 2021; Waaijer et al., 2018). Even though many studies documented how reward structures and incentives in the current academic model led to unintended consequences such as gaming with metrics, manipulative research behavior, misconduct, and strategic publishing practices (Biagioli et al., 2019; Moher et al., 2018; Orhan, 2020), the availability of any incentive beyond fame and popularity could act as another perverse incentive, which would trigger the race for publishing more sensational research at the expense of reliability and validity (Vazire, 2017; Ferguson, 2019). On top of the existing competition that already produces venomous publication bias, researchers would race for constructing a 'wow' effect, which is referred to as the practice of sugar-coating scientific findings, presenting extraordinary evidence, and asserting far-reaching implications to signal novelty that psychology science, in general, suffers from (Jussim et al., 2016; Kruglanski et al., 2017; Clark et al., in press). Nevertheless, even though 13 editorial board members who participated in Rogelberg et al.'s study may have suggested that there are few incentives for engaging with the public, this is a somewhat flawed argument, because fame itself should be a sufficiently rewarding driver for academics and practitioners, as public outreach brings tangible returns (Feist, 2016; McClain, 2017; Gorbatov et al., 2019).

Popularity plays a catalyzing role in the scholarly impact that many aspiring scholars desire. Recent evidence shows that studies by famous authors are more likely to be cited regardless of quality (Brogaard et al., 2020). Meanwhile, it was also found that when a scientific paper receives attention outside of academia and is featured in non-scientific, popular media, its citation again enjoys a significant rise (Anderson et al., 2020). These incentives may encourage scientists to share research findings with larger audiences as increased popularity can be translated into direct academic impact and performance. Additionally, as popularity attracts more popularity, researchers could accumulate more resources, expand their networks, enjoy greater collaboration opportunities as the number of students and colleagues willing to cooperate significantly increases (Merton, 1968, 1988). Likewise, public outreach for practitioners, especially with the increased technological advancements, means personal involvement in scientific conversations, new markets to reach, and new business opportunities to develop (Martin \& MacDonald, 2020; Kang, 2014).

In essence, incentives $d o$ exist for I-O scientists and practitioners if they are willing to dedicate the effort, resources, and commitment needed for public outreach. Rather than the insufficiency of rewards, the availability of existing incentives readily available to IO experts could increase the opportunity cost and risks of going public, which makes more public-facing activities less attractive. The following section attempts to analyze some of the relevant justifications for such resistance. 


\section{Why Do I-O Experts Resist Then?}

\subsection{Competing incentives, opportunity costs, and challenges of going public}

Against the benefits of publicity, I-O experts might still be hesitant to face the public, as indicated by Rogelberg and colleagues, because they lack training or time. Moreover, one may argue that this behavior is a deliberate choice, ascertained after a thoughtful assessment of marginal costs and benefits of going public because such activities require additional resources, efforts, and commitment. Therefore, it is worthwhile to examine the existing benefits that promote habitual scholarly activities and create resistance to not engaging in public-facing activities.

Aguinis et al. (2014) maintained that I-O psychology is dominated by business school scholars who have access to more lucrative resources than their counterparts in psychology departments. The larger pool of employment opportunities, higher salaries, publication bonuses, and competitive rewards readily available at business schools provide a comfortable environment for professors that other activities may not seem financially attractive or worth committing. Therefore, off-duty activities, including engagement with wider audiences, might be regarded as unnecessary overheads (Lindebaum \& Jordan, 2021). Moreover, business school professors could obtain rapid financial gains and insights through executive education opportunities by interacting with corporate leaders in customized, short educational programs that require relatively less effort (Markides, 2007; Pfeffer \& Fong, 2002; Zell, 2001). Thus, scholars may find no meaningful interest in engagement beyond this managerial elite and may consider other extracurricular activities as time-consuming and futile, if they are not sufficiently rewarding in monetary terms. As the skills associated with I-O psychology are marketable in the corporate sphere and business schools' world, professional activities might be economically more profitable than public-facing activities.

Similarly, faculty members at psychology departments may prefer dedicating their scarce resources to grant funding applications that are highly valued or even materialized as a mandatory requirement for tenure in psychology departments (Aguinis et al., 2014). Finally, regardless of where they operate, faculty members conceive that publications in top journals are the only credible currency that counts and illustrates scholarly competence, key to ensuring internationally competitive career opportunities in academia (Aguinis et al., 2020). Therefore, engaging with the public might carry opportunity costs that I-O scientists would not want to bear.

Besides these costs, there are certain challenges involved in mass communication that could contradict the epistemological tenets of science. Even though most rewards and recognitions are structured individually, I-O psychology, as with most sciences, inevitably relies on team effort. Research confirms that the number of co-authors in scientific publications has been rising significantly in the last decade (Moshontz et al., 2021). As the contemporary publishing model transformed researchers from authors to contributors, it may not always be clear how the roles and responsibilities among researchers are allocated. Consequently, it becomes more ambiguous who should get credit for knowledge creation, dissemination, and representation (Simonton, 2016). Thus, building a public-facing persona as a knowledge producer and disseminator at the same time has inevitably become more complex and time-consuming.

More importantly, norms in public communications vastly differ from those in academia. 
Disseminating scientific communication to broader masses has been getting more trivial in an era where virtually everyone strives for public attention by constantly communicating messages, including fake news, disinformation, alternative facts, and pseudoscience. In such a noisy environment, scientists are not only expected to increase their visibility by engaging with the public, but they also need to preserve their integrity and battle against misinformation by conveying interesting, attention-grabbing, and relevant messages linking robust, evidence-based research (McClain, 2017). However, keeping up with the latest research is not an easy task for scholars, as the number of new studies published every day has been skyrocketing (Chu \& Evans, 2021). Simply, scholars may not have enough cognitive resources to deal with the complexities of public-facing activities while staying up to date about all the developments in the field and sustaining their job requirements that are getting overly demanding.

Undoubtedly, scholars desire to make an impact with their research and practitioners with their interventions. Ideally, they should strive to share them with broader masses. However, not every type of research or intervention is suitable for making an impact that could be shared publicly. Feist (2016) argues that impact in science lies on a continuum being from mundane to transformational and revolutionary. In mundane research, scholars imitate each other, and the field gets very little or no advancement. Thus, individuals imitating others have no chances of fame or popularity. In contrast, in rare cases of transformative and revolutionary research (practice), the entire field observes a substantial shift, and individuals who contribute to such paradigm shifts enjoy the greatest fame. We believe that why I-O professionals do not (prefer) to engage with the public has much deeper roots, and the real challenge is that our research has become increasingly mundane, irrelevant, more difficult to read, hard to interpret, and even harder to translate into practice (Tourish, 2020; Cronin et al., 2021). The publication system has become a structural barrier damaging the interaction between research and practice, therefore, it needs further scrutiny.

\subsection{It's not resistance, but suffering: Structural barriers to going public}

More worryingly -potentially, more reasonably-, actual reasons for not engaging in publicfacing activities might be that I-O experts have very little to share outside academic circles. The American Association for the Advancement of Science (AAAS) defines 'public engagement with science' as "intentional, meaningful interactions that provide opportunities for mutual learning between scientists and members of the public" (AAAS, n.d.). In order to meaningfully engage with the public, mutual learning is a fundamental condition. To initiate a two-way communication, not only do scientists need to inform the public, but they should also learn from them and understand what matters to them. To convey compelling and persuasive messages, IO professionals need to make timely and relevant contributions that the public find worthwhile to follow. On many occasions, however, I-O scholars and practitioners admitted that the current system has lost its way and derailed significantly from its original ideas due to overemphasis on scholarship activities; predominantly publishing on top journals (Rupp \& Beal, 2007; Highhouse et al., 2020). Moreover, criticisms also included that research in top journals becomes less credible, overly meaningless, and publishing has evolved as a game more than a journey for 
intellectual pursuit (Tourish, 2020; Köhler et al., 2020; Aguinis et al., 2020).

The problem in I-O science is that our research is getting utterly monotonic and mundane, less readable, repetitive, and overly obsessed with quantitative methodologies and theoretical advancements though they are often incremental (Highhouse et al., 2020; Cronin et al., 2021). As illustrated by Highhouse et al. (2020, p.287), some SIOP members believe that the researchpractice gap is widening and blame the journals for not keeping up with the developments in the actual workplace. They also argue that the emphasis on quantitative research methods, which have become exceedingly esoteric, led to a situation in which it is virtually impossible for practitioners to read, let alone publish, in I-O journals. Even scientists shared similar concerns since publishing has become a real burden in top I-O outlets due to endless rounds of reviews causing significant delays in publication (For a complete picture, please refer to Table 8 in Highhouse et al., 2020).

To understand the severity of the abovementioned problems, it is enough to inspect the Top 10 Workplace Trends, published by SIOP every year based on members' perceptions about the most significant issues impacting the workplace and compare how these trends were captured by our flagship journals. As an illustration, 'artificial intelligence' was on the top of the list in 2019 and 2020 and among the top 5 trends in 2017 and 2018. Yet ironically, on this topic, no single publication has appeared ${ }^{1}$ in the Journal of Applied Psychology, Personnel Psychology, Journal of Organizational Behavior, Journal of Vocational Behavior, and in many others to date. This sign alone, beyond many others, indicates that IO scholarship needs to put considerable efforts to better integrate science and practice.

The disconnect between practice and scholarship in I-O psychology was also acknowledged at the echelon of editorial offices. For example, to overcome this problem, the Practice Forum was introduced in the IOP journal in its Dec 2016 issue and is still alive. The purpose of this platform was stated as:

"to advance the understanding of effective practice of industrial-organizational (I-O) psychology through the publication of original manuscripts focusing on I-O practice issues. The Forum provides practitioners with an outlet for communicating and/or learning about current trends, lessons-learned, best practices, effective practice principles, relevant issues, different points of view, and implementation challenges, associated with practice in I-O psychology" (IOP, 2017).

Looking back at its five years of operation, the Practice Forum hosted 12 manuscripts, of which seven of them were written purely by practitioners. In fact, since the March 2017 issue, there has been an increasing number of academics conquering this section. In the last two years, academics co-authored five out of the seven published articles. Even though initially intended and reserved for practitioners, academics did not shy away from dominating the section originally devoted to practitioners.

This is indicative of the priority among scholars to publish papers in scientific journals beyond spending their time actually engaging with the public. To become an eminent, highly

\footnotetext{
${ }^{1}$ A Scopus search was performed using the term: "artificial intelligence" in Title, Abstract, Keywords in the top 20 journals determined as the most prestigious by SIOP members in Highhouse et al. (2020). The search results and query information are available on https://osf.io/wfzd6/?view_only=460816abe5b14a3ab58d409eb49af9b8.
} 
prolific scholar, any opportunity to publish is seized at all costs. As the competition rises, compliance with the system brings the greatest returns. Academic publishing's highly formulaic nature leaves no autonomy in choices of communication styles, topics, methodologies, and consequently samples outside the expected standards (Bal, 2020). The abundance of particular research types and overrepresentation of certain samples enforce ontological and epistemological isomorphism in top journals and establish publication norms, while discouraging risk-taking in research and destroying intrinsic incentives for asking interesting questions whose answers are unknown (Bergman \& Jean, 2016; Muthukrishna et al., 2020; Orhan, 2020). This also limits collaboration opportunities for interdisciplinary research and keeps I-O science a closed-circuit system communicating in echo chambers (Ryan \& Ford, 2010). Our research needs more openness, transparency, and inclusive communication with multiple stakeholders.

In parallel, before embarking upon a research project, scholars increasingly evaluate the 'publishability' of such research in top-tier journals. Moreover, they are unlikely to start new studies if they could not predict the hypothesized outcomes. Consequently, research findings are hardly surprising for the scientific community, while even less so for practitioners and the public. Hence, the competitive publication system has led to risk-avoiding, hypothesis-confirming type of research that is of decreasing value to the broader society and the public. At the same time, the field is at its prime, as almost all hypotheses in published research are supported (Kepes \& McDaniel, 2013; O'Boyle et al., 2017). In other words, this has created the ironic paradox that we know everything as research has the strong tendency to find hypotheses supported, yet we know very little in our omniscient field. One more modest conclusion is that our research in I-O science is conducted with short-term aims of obtaining and sustaining employment and advancement of one's career, rather than with the purpose of engaging in communication with either our scholarly community or the wider public. The unfortunate truth is that our publications are written to please editors and reviewers.

\section{Concluding Remarks}

\subsection{The question is not how to go to public; it should be how to add value at first place}

By providing an alternative view, we have sought to provide further insight into the complexity of why I-O scientists and the public are disconnected, and have very little to share. We have unpacked some of the structural issues that need to be addressed, which is a crucial step before starting the discussions of how to communicate to the public. It is rather crucial to highlight that our research needs to be centered around creating value, for the public, as well as for ourselves, that is worth communicating. This way, we can increase our visibility in more engaging and meaningful ways.

There have been a great number of attempts to enhance the impact of I-O psychology, providing some interesting directions for solutions, for example, the special issue by Arnold, Dries and Gabriel (2021) and the initiatives around evidence-based practice (Briner \& Rousseau, 2011). These suggestions, however, tend to refer to individual changes, indicating I-O psychologists should take different initiatives, whereas our analysis shows the structural barriers against such actions. It is also necessary to highlight that we need to enable platforms for more collec- 
tive and inclusive communication opportunities to face the public instead of encouraging individual publicity.

Rather than providing solutions, we would like to indicate the following two directions to further consideration to further address the issues. First, we would like to stress the urgency of understanding public engagement as being bi-directional. We can conclude that it is difficult in the current system for I-O psychologists to engage with the public in their research, but it is virtually impossible for I-O practitioners to engage with and contribute to academic research. Second, given the substantial systemic barriers in our research process, we should engage in rethinking and re-structuring our academic system. We are not the first, and unlikely to be the last, to point out the systemic problems and lack of relevance of I-O psychology research (Grand et al., 2018). It is, however, an exception for scholars to engage in the ongoing debate around our professional values and behavior and to provide recommendations for better practice (Bal et al., 2019). We would like to echo this call to all scholars in our field to take responsibility and to cocreate a different future of I-O psychology.

\section{References}

AAAS. (n.d.). Why public engagement matters. American Association for the Advancement of Science - Center for Public Engagement with Science and Technology. https://www.aaas.org/resources/communication-toolkit/whatpublic-engagement

Aguinis, H., Bradley, K. J., \& Brodersen, A. (2014). Industrial-organizational psychologists in business schools: Brain drain or eye opener?. Industrial and Organizational Psychology: Perspectives on Science and Practice, 7(3), 284303. https://doi.org/10.1111/iops.12151

Aguinis, H., Cummings, C., Ramani, R. S., \& Cummings, T. G. (2020). "An A is an A": The new bottom line for valuing academic research. Academy of Management Perspectives, 34(1), 135-154. https://doi.org/10.5465/amp.2017.0193

Anderson, P. S., Odom, A. R., Gray, H. M., Jones, J. B., Christensen, W. F., Hollingshead, T., ... \& Seeley, M. K. (2020). A case study exploring associations between popular media attention of scientific research and scientific citations. PloS One, 15(7), e0234912. https://doi.org/10.1371/journal.pone.0234912

Arnold, J., Dries, N. \& Gabriel, Y. (2021). EJWOP Special Issue: Enhancing the social impact of research in work and organizational psychology - Beyond academia. European Journal of Work and Organizational Psychology, 30(3), 329-338. https://doi.org/10.1080/1359432X.2021.1915293

Bal, P. M., Dóci, E., Lub, X., Van Rossenberg, Y. G., Nijs, S., Achnak, S., Briner, R. B., Brookes, A., Chudzikowski, K., De Cooman, R. ....., van Zelst, M. (2019). Manifesto for the future of work and organizational psychology. European Journal of Work Organizational Psychology, 28(3), 289-299. https://doi.org/10.1080/1359432X.2019.1602041.

Bal, P. M. (2020). Why we should stop measuring performance and well-being. Zeitschrift für Arbeits-und Organisationspsychologie, 64(3), 196-215. https://doi.org/10.1026/0932- 4089/a000333

Bergman, M. E., \& Jean, V. A. (2016). Where have all the "workers" gone? A critical analysis of the unrepresentativeness of our samples relative to the labor market in the industrial- organizational psychology literature. Industrial and Organizational Psychology: Perspectives on Science and Practice, 9(1), 84-113. https://doi.org/10.1017/iop.2015.70

Biagioli, M., Kenney, M., Martin, B. R., \& Walsh, J. P. (2019). Academic misconduct, misrepresentation and gaming: A reassessment. Research Policy, 48(2), 401-413. https://doi.org/10.1016/j.respol.2018.10.025

Briner, R. B., \& Rousseau, D. M. (2011). Evidence-based I-O psychology: Not there yet. Industrial and Organizational Psychology: Perspectives on Science and Practice, 4(1), 3- 22. https://doi.org/10.1111/j.1754-9434.2010.01287.x

Brogaard, J., Engelberg, J., Eswar, S., Van Wesep, E. (2020). On the causal effect offame on citations. SSRN. Available at http://doi.org/10.2139/ssrn.3565487

Chu, J. S., \& Evans, J. A. (2021). Slowed canonical progress in large fields of science. Proceedings of the National Academy of Sciences, 118(41). e2021636118. https://doi.org/10.1073/pnas.2021636118

Clark, C. J., Honeycutt, N., \& Jussim, L. (in press). Replicability and the psychology of science. In S. Lilienfeld, A. Masuda, \& W. O’Donohue (Eds.), Questionable research practices in psychology. New York: Springer. 
Cronin, M. A., Stouten, J., \& van Knippenberg, D. (2021). The theory crisis in management research: Solving the right problem. Academy of Management Review, 46(4), 667-683. https://doi.org/10.5465/amr.2019.0294

Edwards, M. A., \& Roy, S. (2017). Academic research in the 21st century: Maintaining scientific integrity in a climate of perverse incentives and hypercompetition. Environmental Engineering Science, 34(1), 51-61. https://doi.org/10.1089/ees.2016.0223

Feist, G. J. (2016). Intrinsic and extrinsic science: A dialectic of scientific fame. Perspectives on Psychological Science, 11(6), 893-898. https://doi.org/10.1177/1745691616660535

Ferguson, C. J. (2019). The fame monster: Unintended consequence of fame for psychological science. New Ideas in Psychology, 54, 35-39. https://doi.org/10.1016/j.newideapsych.2019.01.003

Grand, J. A., Rogelberg, S. G., Allen, T. D., Landis, R. S., Reynolds, D. H.,Scott, J. C., Tonidandel, S., \&. Truxillo, D. M. (2018). A systems-based approach to fostering robust science in industrial-organizational psychology. Industrial and Organizational Psychology: Perspectives on Science and Practice, 11(1), 4-42. https://doi.org/10.1017/iop.2017.55

Gorbatov, S., Khapova, S. N., \& Lysova, E. I. (2019). Get noticed to get ahead: The impact of personal branding on career success. Frontiers in Psychology, 10, 2662. https://doi.org/10.3389/fpsyg.2019.02662

Harvey, L. (2020). Research fraud: a long-term problem exacerbated by the clamour for research grants. Quality in Higher Education, 26(3), 243-261. https://doi.org/10.1080/13538322.2020.1820126

Highhouse, S., Zickar, M. J., \& Melick, S. R. (2020). Prestige and relevance of the scholarly journals: Impressions of SIOP members. Industrial and Organizational Psychology: Perspectives on Science and Practice, 13(3), 273290. https://doi.org/10.1017/iop.2020.2

IOP. (2017). Introducing a new IOP Practice Forum. IOP Practice Forum. Internet Archive. https://web.archive.org/web/20171105191832/https://www.cambridge.org/core/journals/industrial-and-organizational-psychology/iop-practice-forum

Jussim, L., Crawford, J. T., Anglin, S. M., Stevens, S. T., \& Duarte, J. L. (2016). Interpretations and methods: Towards a more effectively self-correcting social psychology. Journal of Experimental Social Psychology, 66, 116-133. https://doi.org/10.1016/j.jesp.2015.10.003

Kang, M. (2014). Understanding public engagement: Conceptualizing and measuring its influence on supportive behavioral intentions, Journal of Public Relations Research, 26(5), 399-416. https://doi.org/10.1080/1062726X.2014.956107

Kepes, S., \& McDaniel, M. A. (2013). How trustworthy is the scientific literature in industrial and organizational psychology? Industrial and Organizational Psychology: Perspectives on Science and Practice, 6(3), 252-268. https://doi.org/10.1111/iops.12045

Köhler, T., DeSimone, J. A., \& Schoen, J. L. (2020). Prestige does not equal quality: Lack of research quality in highprestige journals. Industrial and Organizational Psychology: Perspectives on Science and Practice, 13(3), 321327. https://doi.org/10.1017/iop.2020.53

Kruglanski, A. W., Chernikova, M., \& Jasko, K. (2017). Social psychology circa 2016: A field on steroids. European Journal of Social Psychology, 47(1), 1-10. https://doi.org/10.1002/ejsp.2285

Lindebaum, D., \& Jordan, P. J. (2021). Publishing more than reviewing? Some ethical musings on the sustainability of the peer review process. Organization, 13505084211051047. Advance online publication. https://doi.org/10.1177/13505084211051047

Markides, C. (2007). In search of ambidextrous professors. Academy of Management Journal, 50(4), 762-768. https://doi.org/10.5465/amj.2007.26279168

Martin, C., \& MacDonald, B. H. (2020). Using interpersonal communication strategies to encourage science conversations on social media. PLoS One, 15(11), e0241972. https://doi.org/10.1371/journal.pone.0241972

McClain, C. R. (2017) Practices and promises of Facebook for science outreach: Becoming a "Nerd of Trust". PLoS Biology, 15(6), e2002020. https://doi.org/10.1371/journal.pbio.2002020

Merton, R. K. (1968). The Matthew effect in science: The reward and communication systems of science are considered. Science, 159(3810), 56-63. https://doi.org/10.1126/science.159.3810.56

Merton, R. K. (1988). The Matthew effect in science, II: Cumulative advantage and the symbolism of intellectual property. Isis: A Journal of the History of Science Society, 79(4), 606-623. https://doi.org/10.1086/354848

Moher, D., Naudet, F., Cristea, I. A., Miedema, F., Ioannidis, J. P., \& Goodman, S. N. (2018). Assessing scientists for hiring, promotion, and tenure. PLoS Biology, 16(3), e2004089. https://doi.org/10.1371/journal.pbio.2004089

Moshontz, H., Ebersole, C. R., Weston, S. J., \& Klein, R. A. (2021). A guide for many authors: Writing manuscripts in large collaborations. Social and Personality Psychology Compass, 15(4), e12590. https://doi.org/10.1111/spc3.12590

Muthukrishna, M., Bell, A. V., Henrich, J., Curtin, C. M., Gedranovich, A., McInerney, J., \& Thue, B. (2020). Beyond Western, Educated, Industrial, Rich, and Democratic (WEIRD) psychology: Measuring and mapping scales of cultural and psychological distance. Psychological Science, 31(6), 678-701. 
https://doi.org/10.1177/0956797620916782

O’Boyle Jr, E. H., Banks, G. C., \& Gonzalez-Mulé, E. (2017). The chrysalis effect: How ugly initial results metamorphosize into beautiful articles. Journal of Management, 43(2), 376- 399. https://doi.org/10.1177/0149206314527133

Orhan, M. A. (2020). Pardon my French: On superfluous journal rankings, incentives, and impacts on industrial-organizational psychology publication practices in French business schools. Industrial and Organizational Psychology: Perspectives on Science and Practice, 13(3), 295-306. https://doi.org/10.1017/iop.2020.59

Pfeffer, J., \& Fong, C. T. (2002). The end of business schools? Less success than meets the eye. Academy of Management Learning \& Education, 1(1), 78-95. https://doi.org/10.5465/amle.2002.7373679

Rogelberg, S. G., King, E. B., Alonso, A. (2022). How we can bring I-O psychology science and evidence-based practices to the public. Industrial and Organizational Psychology: Perspectives on Science and Practice, 15(2), Advance online publication.

Rupp, D. E., \& Beal, D. (2007). Checking in with the scientist-practitioner model: How are we doing. The IndustrialOrganizational Psychologist, 45(1), 35-40.

Ryan, A. M., \& Ford, J. K. (2010). Organizational psychology and the tipping point of professional identity. Industrial and Organizational Psychology: Perspectives on Science and Practice, 3(3), 241-258. https://doi.org/10.1111/j.1754-9434.2010.01233.x

Simonton, D. K. (2016). Giving credit where credit's due: Why it's so hard to do in psychological science. Perspectives on Psychological Science, 11(6), 888-892. https://doi.org/10.1177/1745691616660155

Smaldino, P. E., \& McElreath, R. (2016). The natural selection of bad science. Royal Society Open Science, 3(9), 160384.https://doi.org/10.1098/rsos.160384

Sommers, S. R. (2018). The public: Engaging a nonscholarly audience. In L. R. Tropp (Ed.), Making research matter: A psychologist's guide to public engagement (pp. 41-56). American Psychological Association. http://www.jstor.org/stable/j.ctv1chrtdm.7

Tourish, D. (2020). The triumph of nonsense in management studies. Academy of Management Learning \& Education, 19(1), 99-109. https://doi.org/10.5465/amle.2019.0255

van Dalen, H. P. (2021). How the publish-or-perish principle divides a science: The case of economists. Scientometrics, 126(2), 1675-1694. https://doi.org/10.1007/s11192-020- 03786-x

Vazire, S. (2017). Quality uncertainty erodes trust in science. Collabra: Psychology, 3(1), 1. https://doi.org/10.1525/collabra.74

Waaijer, C. J., Teelken, C., Wouters, P. F., \& van der Weijden, I. C. (2018). Competition in science: Links between publication pressure, grant pressure and the academic job market. Higher Education Policy, 31(2), 225-243. https://doi.org/10.1057/s41307-017-0051-y

Zell, D. (2001). The market-driven business school: Has the pendulum swung too far?. Journal of Management Inquiry, 10(4), 324-338. https://doi.org/10.1177/1056492601104006 